\title{
Considerações experimentais sobre os efeitos do controle por rejeição na formação de classes de equivalência*
}

\section{Experimental accounts about the effects of rejection control in the equivalence class formation}

\section{Consideraciones experimentales sobre los efectos del control por rechazo en la formación de clases de equivalencia}

\section{Edson Massayuki Huziwara', Átila Moreira Cedro², Eduardo Cunha Vilela ${ }^{3}$, Henrique Mesquita Pompermaier ${ }^{4}$, Maria Clara Rabelo Ferreira Silva ${ }^{5}$, Marina Mendonça de Sousa ${ }^{6}$, Naiene dos Santos Pimental ${ }^{7}$}

[1] [2] [3] [5] [6] Universidade Federal de Minas Gerais [4] [7] Universidade Federal de São Carlos | Título abreviado: Controle por rejeição e classes de equivalência I Endereço para correspondência: Rua Córrego da Mata, n.590, apto. 901 - Bloco 1. Bairro Horto. Belo Horizonte - MG. CEP: $31030-030$ I Email: huziwara.edson@gmail.com

\begin{abstract}
Resumo: Experimentos que investigam questões relacionadas à ocorrência de resultados negativos em testes de formação de classes de equivalência referem-se frequentemente ao estabelecimento do controle por rejeição (i.e., relação modelo/S-). Com base nas análises teóricas e empíricas descritas nos estudos seminais, argumentou-se que o estabelecimento de tais relações daria origem a padrões de respostas que seriam opostos àqueles geralmente descritos em testes de reflexividade e transitividade. No entanto, a maioria dos experimentos feitos posteriormente com procedimentos específicos para estabelecer o controle por rejeição em seus participantes obtiveram resultados negativos nos testes de formação de classes, mas não obtiveram os padrões opostos de respostas. Portanto, uma descrição detalhada dos efeitos nos testes de formação de classe modulados pelo estabelecimento de relações condicionais controladas por rejeição parece ainda necessária. Vinte e três estudantes universitários realizaram um procedimento de matching-to-sample (MTS) que estabelecia o controle por rejeição por meio de quantidades diferentes de $\mathrm{S}+\mathrm{e} \mathrm{S}$-. Os resultados indicaram que os participantes obtiveram resultados negativos em testes de formação de classes e não foi possível identificar qualquer padrão de respostas entre eles, a exemplo do ocorrido em experimentos anteriores. À luz desses resultados, discute-se a necessidade de novas estratégias relacionadas à avaliação da ocorrência desse processo comportamental tão frequentemente mencionado.
\end{abstract}

Palavras-chave: controle por rejeição, testes de formação de classes, padrões opostos de resposta, estudantes universitários.

\footnotetext{
“Pesquisa financiada pelo CNPq (edital Universal - processo 472407/2013-9). A realização do presente projeto também recebeu suporte financeiro do Instituto Nacional de Ciência e Tecnologia sobre Comportamento, Cognição e Ensino (INCT-ECCE) com financiamento da FAPESP (processo 2008/57705-8) e do CNPq (processo 573972/2008-7)"
} 


\begin{abstract}
Experiments that investigate issues related to the occurrence of negative results in the equivalence class formation tests frequently refer to the establishment of the reject control (i.e., sample/S- relation). Based on the theoretical and empirical analysis described in the seminal studies, it was argued that the establishment of such relations would give rise to patterns of responses that would be opposite to those generally described in reflexivity and transitivity tests. However, most posterior experiments with specific procedures to establish relations controlled by rejection in their participants obtained negative results in the class formation tests, but did not obtain the opposite pattern of responses. Therefore, a detailed description of effects in the class formation tests modulated by the establishment of conditional relations controlled by rejection is still necessary. Twenty-three college students performed a procedure of matching-to-sample with different numbers of $\mathrm{S}+$ and $\mathrm{S}$ - which established control by rejection. The result seems to indicate that participants achieved negative results in classes of deformation tests and there was no pattern of responses among them, as described in previous experiments. Based on these results, we discuss the need for new strategies related to the evaluation of occurrence of this behavioral process many times mentioned.
\end{abstract}

Keywords: rejection control, equivalence class formation tests, opposite pattern of responses, college students

Resumen: Experimentos que investigan cuestiones relacionadas a la ocurrencia de resultados negativos en testes de formación de clases de equivalencia se refieren frecuentemente al establecimiento del control por rechazo (o sea, relación modelo/S-). Basado en el análisis teórico y empírico descrito en el estudio seminal, se argumentó que el establecimiento de tales relaciones daría origen a patrones de respuestas que serían opuestos a aquellos generalmente descritos en testes de reflexividad y transitividad. No obstante, la mayoría de los experimentos realizados posteriormente con procedimientos específicos para establecer el control por el rechazo de sus participantes obtuvieron resultados negativos en los testes de formación de clases, pero no obtuvieron los patrones opuestos de respuestas. Por lo tanto, una descripción detallada de los efectos en los testes de formación clase modulados por el establecimiento de relaciones condicionales controladas por rechazo parece aún necesaria. Veintitrés estudiantes universitarios realizaron un procedimiento de matching-to-sample (MTS) que establecía el control por rechazo por medio de la utilización de cuantidades diferentes de S+ e S-. Los resultados indicaron que los participantes obtuvieron resultados negativos en testes deformación de clases y no fue posible identificar cualquier patrón de respuestas entre ellos, a ejemplo del ocurrido en experimentos anteriores. A la luz de esos resultados, se discute la necesidad de nuevas estrategias relacionadas a evaluación de la ocurrencia de ese proceso comportamental tan frecuentemente nombrado.

Palabras-clave: control por rechazo, testes de formación de clases, patrones opuestos de respuesta, estudiantes universitarios 
Experimentos sobre a formação de classes de estímulos equivalentes são, em geral, iniciados com o ensino de um conjunto basal de relações condicionais (também chamadas de relações de linha de base). Podem ser ensinadas, por exemplo, relações condicionais entre estímulos de três conjuntos (i.e., estímulos A1 e A2 do conjunto A; estímulos B1 e B2 do conjunto B; e estímulos $\mathrm{C} 1$ e C2 do conjunto C). No procedimento de matching to sample (MTS), o Treino AB é organizado de forma a apresentar, em cada tentativa, um dos estímulos do conjunto A como estímulo modelo e ambos os estímulos do conjunto B como estímulos de comparação. Nas tentativas em que A1 é apresentado como modelo, o estímulo de comparação B1 exerce a função de $\mathrm{S}+$ (estímulo correlacionado com a obtenção do reforço) e o estímulo de comparação B2 exerce a função S- (estímulo correlacionado com a extinção). Ademais, nas tentativas em que A2 é apresentado como modelo, o comparação B1 exerce a função de $S-$ e B2 exerce a função $S+$. Uma vez aprendidas as relações condicionais entre os estímulos dos conjuntos $\mathrm{A}$ e $\mathrm{B}$, tem início o Treino BC. Nesse segundo treino, os estímulos do conjunto B são apresentados como estímulos modelo e os estímulos do conjunto $\mathrm{C}$ como estímulos de comparação. $\mathrm{O}$ comparação $\mathrm{C} 1$ exerce a função de $\mathrm{S}+$ e $\mathrm{C} 2$ exerce a função de $\mathrm{S}$ - diante do modelo B1; diante do modelo B2, por sua vez, $\mathrm{C} 1$ exerce a função de $\mathrm{S}-$ e $\mathrm{C} 2$ exerce a função de $\mathrm{S}+$. Consequências diferenciais que sinalizam respostas corretas e incorretas em cada tentativa são fornecidas durante ambos os treinos (e.g., Sidman, 1994, 2000; Sidman \& Tailby, 1982).

Tendo sido exposto aos Treinos AB e BC, um participante pode estabelecer novas relações condicionais (também chamadas de relações emergentes) sem a necessidade de treino adicional (e.g., Sidman, 1994, 2000; Sidman \& Tailby, 1982). A relação emergente denominada de reflexividade, por exemplo, é definida como sendo a relação do elemento consigo próprio, ou seja, An R An (no qual An pode ser qualquer elemento de um conjunto sob consideração e $\mathrm{R}$ a relação entre ambos). A simetria é definida como sendo a permutabilidade das funções de modelo e comparação entre estímulos relacionados durante os treinos, ou seja, o aprendizado da relação An R Bn deve possibilitar a emergência da relação Bn R An. Finalmente, a transitividade é definida pela existência de relações condicionais entre estímulos não diretamente relacionados, mas que foram relacionados a um terceiro estímulo comum durante o treino de linha de base, ou seja, o aprendizado das relações An R Bn e Bn R Cn deve possibilitar a emergência da relação An R Cn (de Rose, 1993; Sidman, 1994, 2000; Sidman \& Tailby, 1982). Caso seja comprovada a existência simultânea de relações reflexivas, simétricas e transitivas para um mesmo conjunto de estímulos, então é possível afirmar que o treino condicional de linha de base originou uma classe de estímulos equivalentes.

Desde o trabalho seminal de Sidman, em 1971, um número considerável de estudos discutiu questões experimentais e teóricas acerca das condições necessárias e suficientes para o estabelecimento de classes de estímulos equivalentes (e.g., Carr, Wilkinson, Blackman, \& Mcllvane, 2000; Carrigan \& Sidman, 1992; Devany, Hayes, \& Nelson, 1986; Horne \& Lowe, 1996; Sidman, 1994, 2000, 2008; Sidman \& Cresson, 1973; Sidman \& Tailby, 1982). De maneira complementar, durante esse período também foram conduzidos experimentos para investigar aspectos que poderiam estar relacionados aos fracassos em se estabelecer tais classes (e.g., Dube \& McIlvane, 1996; Goulart, Mendonça, Barros, Galvão, \& McIlvane, 2005; Kato, de Rose, \& Faleiros, 2008; McIlvane \& Dube, 1992, 2003; Mcllvane, Serna, Dube, \& Stromer, 2000). Dentre os aspectos utilizados para justificar resultados negativos, o estabelecimento de relações condicionais controladas por rejeição durante o ensino das relações de linha de base é assunto recorrente em diversos estudos na literatura (Carrigan \& Sidman, 1992; de Almeida, 2013; Johnson \& Sidman, 1993; Perez \& Tomanari, 2008, 2013; Sidman, 1978, 1987, 1994). Para melhor descrever relações controladas por rejeição, Carrigan e Sidman propuseram a divisão didática de uma relação condicional em dois itens. O primeiro item é o par de estímulos relacionados durante o ensino; o segundo item é o componente comportamental que define a maneira pela qual os estímulos modelo e de comparação estão relacionados. Caso o responder esteja sob controle de seleção, o par de estímulos relacionados é constituído pelo modelo e o estímulo de comparação correto ou $\mathrm{S}+$ (e.g., A1 e B1), sendo o componente comportamental descrito como "escolher" (i.e., se A1, então 
escolher B1). Entretanto, caso o responder seja controlado por rejeição, o par de estímulos relacionados é constituído pelo modelo e o estímulo de comparação incorreto ou S- (e.g., A1 e B2), sendo o componente comportamental descrito como "não escolher" (i.e., se A1, então não escolher B2). Independente da ocorrência do controle por seleção ou rejeição, o participante efetivamente escolhe o estímulo B1, ou seja, emite a resposta designada como correta. Apesar de o controle por rejeição não impedir a obtenção dos critérios de aprendizagem estabelecidos para o ensino das relações de linha de base, ele pode ser responsável por alterar consideravelmente os resultados que normalmente são encontrados em testes de formação de classes de estímulos equivalentes.

A partir do exemplo de treino sugerido anteriormente e supondo que o responder do participante seja controlado por seleção, duas classes de estímulos equivalentes seriam formadas, a saber, a classe composta por A1, B1e C1 (i.e., Classe I) e a classe composta por A2, B2 e C2 (i.e., Classe II). As considerações realizadas a seguir descrevem apenas as relações previstas para os estímulos da Classe I, porém, o mesmo raciocínio pode ser aplicado aos estímulos da Classe II. Portanto, segundo Carrigan e Sidman (1992), as relações condicionais estabelecidas na linha de base seriam:

- se A1, então escolher B1 - o participante escolhe o comparação B1;

- se B1, então escolher C1 - o participante escolhe o comparação C1.

Nesse caso, todas as relações emergentes entre estes estímulos seriam mediadas pelo componente comportamental "escolher". Portanto, seriam exemplos de relações reflexivas:

- se A1, então escolher A1 - o participante escolhe o comparação A1;

- se B1, então escolher B1 - o participante escolhe o comparação B1;

- se C1, então escolher C1 - o participante escolhe o comparação C1.

Seriam exemplos de relações de simetria:

- se B1, então escolher A1 - o participante es- colhe o comparação A1;

- se C1, então escolher B1 - o participante escolhe o comparação B1.

E, também, seria exemplo de relação transitiva:

- se A1, então escolher C1 - o participante escolhe o comparação C1.

Por outro lado, ao considerar a ocorrência do controle por rejeição em um treino como o proposto anteriormente, a Classe I seria composta por A1, B2 e C1. A Classe II, por sua vez, seria composta por A2, B1 e C2. Novamente, a descrição das relações condicionais estabelecidas considerará apenas as relações da Classe I, sendo possível derivar o mesmo processo para a Classe II. Assim teríamos:

- se A1, então não escolher B2 - o participante escolhe o comparação B1;

- se B2, então não escolher C1 - o participante escolhe o comparação C2.

Assim sendo, todas as relações emergentes entre tais estímulos seriam mediadas pelo componente comportamental "não escolher". Relações condicionais emergentes que poderiam ser chamadas de reflexivas seriam:

- se A1, então não escolher A1 - o participante escolhe o comparação A2;

- se B2, então não escolher B2 - o participante escolhe o comparação B1;

- se C1, então não escolher C1 - o participante escolhe o comparação C2.

Exemplos de relações de simetria seriam:

- se B2, então não escolher A1 - o participante escolhe o comparação A2;

- se C1, então não escolher B2 - o participante escolhe o comparação B1.

E um exemplo de relação condicional emergente transitiva seria:

- se A1, então não escolher C1 - o participante escolhe o comparação C2. 
Desse modo, quando comparados os resultados em testes que avaliam as relações condicionais emergentes de reflexividade e transitividade, controles por seleção e rejeição deveriam originar desempenhos completamente opostos. No que concerne especificamente aos testes de transitividade, ainda há outra variável a ser considerada, a saber, a quantidade de conjuntos nodais envolvida durante o ensino. O termo "conjunto nodal" refere-se ao conjunto composto pelos estímulos que são relacionados diretamente a dois outros estímulos durante o treino. Em um treino $\mathrm{AB}-\mathrm{BC}$, por exemplo, existe apenas um conjunto nodal, o conjunto B. Caso o treino seja realizado entre $\mathrm{AB}-\mathrm{BC}-\mathrm{CD}$, serão dois os conjuntos nodais, B e C (cf., Fields \&Verhave, 1987).

Ao considerar, por exemplo, a ocorrência de respostas controladas por rejeição durante o ensino de relações condicionais entre os estímulos dos conjuntos $\mathrm{A}, \mathrm{B}, \mathrm{C}$ e $\mathrm{D}$, as relações que se formariam seriam:

- se A1, então não escolher B2;

- se B2, então não escolher C1;

- se C1, então não escolher D2.

Nesse caso, novamente considerando apenas as relações formadas para a Classe I, os estímulos relacionados durante o treino seriam A1, B2, C1, D2 e todas as relações emergentes entre esses estímulos seriam mediadas pelo componente comportamental "não escolher". Por transitividade, a relação condicional envolvendo os estímulos A1 e D2 seria descrita como "se A1, então não escolher D2". Nesse caso, o participante escolheria o estímulo de comparação D1. Ocorre que, a escolha do comparação D1 diante do modelo A1 também é um desempenho esperado em participantes cujo responder é controlado por seleção. Em resumo, de acordo com as análises teóricas de Carrigan e Sidman (1992), os resultados obtidos em testes de transitividade serão opostos para respostas controladas por seleção ou rejeição quando o par de estímulos analisado for separado por um número ímpar de conjuntos nodais (p. ex., testes AC ou BD - um conjunto nodal); mas, serão idênticos quando tais estímulos forem separados por um número par de conjuntos nodais (p. ex., testes $\mathrm{AD}$ - dois conjuntos nodais).
O experimento conduzido por Johnson e Sidman (1993) teve por objetivo induzir a ocorrência de relações condicionais controladas por rejeição e avaliar os resultados obtidos nos testes de formação de classes de estímulos equivalentes. Esse experimento contou com a participação de três adultos com desenvolvimento típico. Para induzir o controle por rejeição, os autores utilizaram um procedimento em que diferentes quantidades de estímulos exerceram as funções de S+ e S-. Cada estímulo modelo foi relacionado a um único estímulo de comparação com função de S- e a quatro estímulos de comparação com função de S+. Por exemplo, tentativas que apresentavam como modelo o estímulo A1 sempre continham o estímulo de comparação B2 exercendo a função de S-, mas alternavam a apresentação de um de quatro estímulos que exerciam a função de $\mathrm{S}+(\mathrm{B} 1, \mathrm{X} 1, \mathrm{X} 2$ ou $\mathrm{X} 3$ ). Assim, diante do modelo A1, havia tentativas em que os estímulos de comparação apresentados eram B1 e B2, outras em que a escolha deveria ser realizada entre X1 e B2, e assim, sucessivamente. Para emitir o responder discriminado, o participante podia aprender quatro relações condicionais controladas por seleção (-se A1, escolher B1; -se A1, escolher X1; -se A1, escolher X2; -se A1, escolher X3) ou apenas uma relação condicional controlada por rejeição (-se A1, não escolher B2).

Os resultados obtidos por Johnson e Sidman (1993) comprovaram as previsões realizadas por Carrigan e Sidman (1992), ou seja, nos testes de reflexividade e nos testes de transitividade envolvendo estímulos separados por um número ímpar de conjuntos nodais, os participantes apresentaram desempenhos opostos aos que normalmente são apresentados nos testes de formação de classes equivalentes. Além disso, nos testes de simetria e transitividade envolvendo estímulos separados por um número par de conjuntos nodais, os mesmos participantes apresentaram desempenhos semelhantes aos que são apresentados nos testes quando ocorre o estabelecimento do controle por seleção.

A partir da evidente modulação exercida pela ocorrência do controle por rejeição na formação de classes de equivalência (Carrigan \& Sidman, 1992; Johnson \& Sidman, 1993; Sidman, 1987), esse tópico passou a ser frequentemente associado a resultados negativos em testes de formação de classes. De 
acordo com esses autores, participantes que estabelecem relações de seleção apresentam as relações de equivalência esperadas nos testes de formação de classe, enquanto participantes que estabelecem relações de rejeição provavelmente fracassam em tais testes, presumivelmente por terem formado outras relações de equivalência, incoerentes com aquelas que estão sendo medidas. Os autores afirmam ainda que, utilizando um maior controle experimental sobre as relações estabelecidas no ensino de linha de base, seria possível reduzir ou até mesmo eliminar a ocorrência dos resultados negativos. Sob essa perspectiva, muitos experimentos procuraram descrever maneiras alternativas de produzir, evitar ou identificar a ocorrência do controle por rejeição durante o ensino das relações de linha de base (e.g., Arantes, 2012; de Almeida, 2013; Goulart et al., 2005; Grisante, 2011; Hamasaki, 2009; Huziwara, de Souza, \& Tomanari, no prelo; Kato et al., 2008; Magnunson, 2002; Perez, 2012; Perez \& Tomanari, 2008, 2013; Stromer \& Osbourne, 1992).

$\mathrm{Na}$ grande maioria dos experimentos que utilizaram procedimentos para produzir intencionalmente o controle por rejeição durante o ensino das relações de linha de base, na tentativa de replicar os resultados descritos por Johnson e Sidman (1993), os participantes, de maneira geral, realmente fracassam em obter os critérios nos testes de formação de classes de equivalência. Em contrapartida, não apresentam padrões de escolha completamente opostos àqueles esperados nesses testes quando ocorre o controle por seleção. As porcentagens de respostas condizentes com a formação de classes ficam em torno dos $50 \%$ para a maioria das relações testadas (e.g., Arantes, 2012; Grisante, 2011; Hamasaki, 2009; Huziwara, de Souza et al., no prelo; Kato et al., 2008; ver exceção em Perez, 2012). Assim sendo, ainda parece necessário descrever em um maior nível de detalhes quais seriam os efeitos do controle por rejeição nos testes de formação de classes. Seria possível, por exemplo, que tal efeito fosse observado apenas para as relações transitivas, mas não para as relações reflexivas ou vice-versa? E ainda, porcentagens de acertos abaixo do critério de formação de classes, mas que não sejam exatamente opostos aos esperados poderiam ser considerados evidência de ocorrência de controle por rejeição? Dito de outra forma, mesmo na ausência dos padrões claros e regulares descritos por Johnson e Sidman, seria possível encontrar outras características que fossem comuns a grande maioria dos participantes para caracterizar a ocorrência do controle por rejeição? Respostas a essas e outras perguntas certamente permitiriam um melhor entendimento do processo comportamental envolvido na formação de classes, além de, talvez, adequar a utilização da ocorrência do controle por rejeição como justificativa para os resultados negativos encontrados.

Assim, o objetivo principal do presente experimento consiste em descrever os padrões de resposta nos testes de equivalência em participantes submetidos a procedimentos que estabelecem o controle por rejeição a partir de uma replicação sistemática e extensiva do procedimento realizado por Johnson e Sidman (1993). Além disso, também procurou-se avaliar a eficácia da utilização de diferentes quantidades de S+/S- para favorecer o estabelecimento de relações de rejeição. Esse segundo objetivo está inserido em um contexto maior que propõe identificar quais as variáveis procedimentais que modulariam de forma mais efetiva a ocorrência dessa configuração específica de controle de estímulos.

\section{Método}

\section{Participantes}

O presente experimento contou com a participação voluntária de 23 estudantes universitários. Não havia qualquer restrição com relação à idade ou ao curso de graduação, entretanto, os participantes declararam não possuir qualquer experiência prévia em pesquisas sobre Análise do Comportamento. A Tabela 1 apresenta informações relacionadas à idade, ao sexo e ao curso de graduação de todos participantes.

Antes do início do experimento, todos os participantes foram informados sobre os procedimentos aos quais seriam expostos e assinaram um Termo de Consentimento Livre e Esclarecido. O presente projeto foi aprovado pelo Comitê de Ética em Pesquisa da Universidade Federal de Minas Gerais (CAAE n. ${ }^{\circ}$ 24589614.9.1001.5149). 


\begin{tabular}{|c|c|c|c|c|}
\hline Identificação & Idade & Sexo & Instituição & Curso de Graduação \\
\hline Partic. 01 & 20 anos & Fem. & 01 & Química \\
\hline Partic. 02 & 18 anos & Masc. & 01 & Eng. Mecânica \\
\hline Partic. 03 & 23 anos & Fem. & 01 & Estatística \\
\hline Partic. 04 & 24 anos & Masc. & 01 & Eng. Mecânica \\
\hline Partic. 05 & 22 anos & Masc. & 01 & Psicologia \\
\hline Partic. 06 & 18 anos & Fem. & 01 & Biologia \\
\hline Partic. 07 & 22 anos & Fem. & 01 & Biologia \\
\hline Partic. 08 & 24 anos & Masc. & 01 & Eng. Mecânica \\
\hline Partic. 09 & 26 anos & Masc. & 01 & Eng. Mecânica \\
\hline Partic. 10 & 19 anos & Masc. & 01 & Biologia \\
\hline Partic. 11 & 25 anos & Masc. & 01 & Filosofia \\
\hline Partic. 12 & 26 anos & Masc. & 01 & Eng. Produção \\
\hline Partic. 13 & 22 anos & Fem. & 02 & Psicologia \\
\hline Partic. 14 & 22 anos & Fem. & 02 & Psicologia \\
\hline Partic. 15 & 23 anos & Fem. & 02 & Sist. Informação \\
\hline Partic. 16 & 24 anos & Masc. & 02 & Sist. Informação \\
\hline Partic. 17 & 19 anos & Masc. & 02 & Artes Visuais \\
\hline Partic. 18 & 18 anos & Masc. & 02 & Artes Visuais \\
\hline Partic. 19 & 19 anos & Fem. & 02 & Artes Visuais \\
\hline Partic. 20 & 18 anos & Fem. & 02 & Controladoria de Finanças \\
\hline Partic. 21 & 18 anos & Masc. & 02 & Eng. Aeroespacial \\
\hline Partic. 22 & 19 anos & Masc. & 02 & Eng. Civil \\
\hline Partic. 23 & 19 anos & Masc. & 02 & Eng. Civil \\
\hline
\end{tabular}

\section{Local e equipamentos}

Os dados foram coletados em dois ambientes distintos. O primeiro local (Local 01) utilizado para a realização da coleta de dados era uma sala medindo $3 \mathrm{~m} \times 3 \mathrm{~m}$, equipada com um computador (notebook), uma cadeira e duas mesas dispostas em cantos opostos da sala. O segundo local (Local 02) media $5 \mathrm{~m} \times 3 \mathrm{~m}$ e era equipado com dois computadores. Ambos os ambientes apresentavam boas condições de iluminação e controle de ruídos externos ao experimento.

A apresentação dos estímulos visuais, o registro das respostas emitidas pelos participantes e, quando necessário, a liberação das consequências diferenciais para acertos e erros foram todas tarefas executadas pelo programa Open the Window (Perez \& Clavijo, 2010), instalado em microcomputadores e notebooks equipados com teclados, mouses e fones de ouvido.
Como estímulos visuais foram utilizados 10 fotografias de animais e 26 desenhos bidimensionais coloridos e abstratos. Todos os estímulos mediam aproximadamente $3,5 \mathrm{~cm} \times 3,5 \mathrm{~cm}$ e foram apresentados em espaços na tela do computador que mediam $5 \mathrm{~cm} \times 5 \mathrm{~cm}$.

\section{Tarefa experimental}

Os participantes eram expostos a uma tarefa de MTS que exigia uma resposta adicional para visualizar os estímulos. A tentativa era iniciada com a apresentação de uma tela contendo um modelo encoberto por um quadrado e, imediatamente abaixo, um ícone no qual estava escrito "VER". Clicar com o mouse nesse ícone produzia a retirada do quadrado preto por $0,3 \mathrm{~s}$, período em que o estímulo modelo poderia ser observado. 

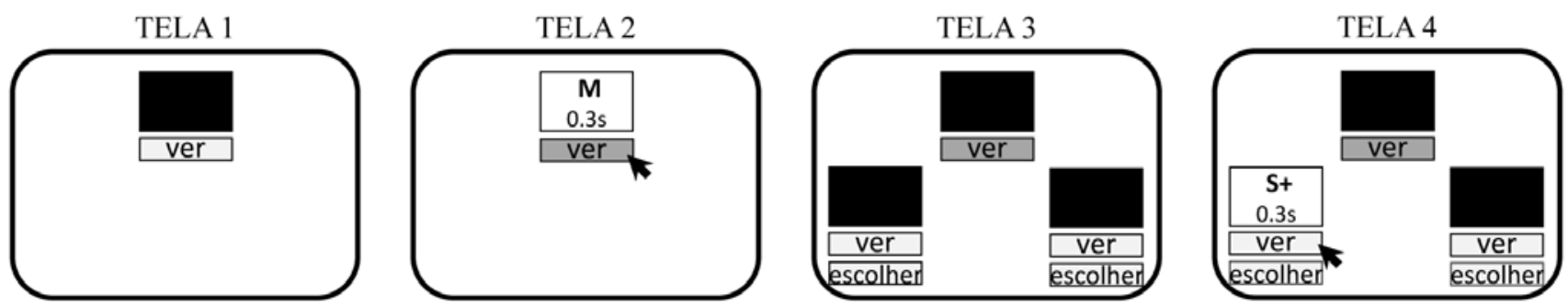

TELA 5

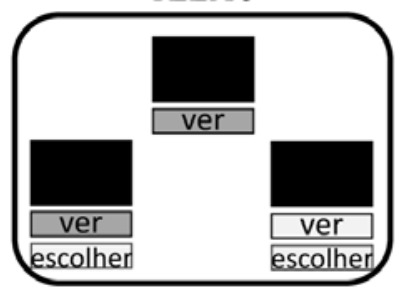

TELA 6

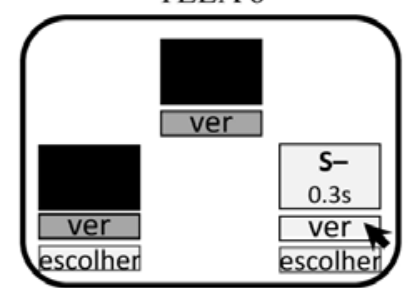

TELA 7

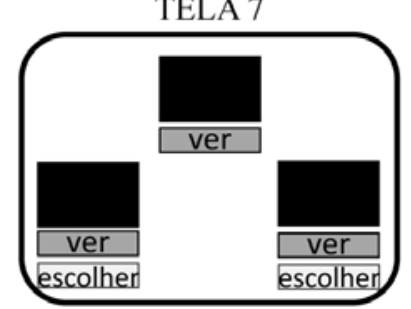

Figura 1. Exemplo da sequência de telas em uma tentativa utilizando o procedimento de MTS com exigência de respostas de observação. Todos os estímulos são apresentados cobertos por um quadrado preto que pode ser retirado clicando com o mouse no ícone "VER" (adaptado de Perez, 2012).

Ao final do período de $0,3 \mathrm{~s}$, o estímulo modelo era coberto pelo quadrado novamente e dois estímulos de comparação eram apresentados na parte inferior da tela. Da mesma forma que o modelo, os estímulos de comparação também estavam cobertos por quadrados pretos e, para observá-los por períodos de $0,3 \mathrm{~s}$, os participantes tinham de clicar nos ícones "VER" localizados imediatamente abaixo de cada um deles. Assim, os estímulos de comparação eram vistos de forma independente e sucessiva e os participantes podiam observá-los apenas uma vez em cada tentativa.

Após visualizar ambos os estímulos de comparação, dois ícones adicionais nos quais estava escrito "ESCOLHER" eram apresentados imediatamente abaixo dos ícones "VER". Caso o participante clicasse no ícone "ESCOLHER" localizado abaixo do estímulo de comparação correto, um ponto era adicionado a um contador localizado no centro da tela e uma sequência de notas musicais ascendentes era apresentada. Caso o participante clicasse no ícone "ESCOLHER" localizado abaixo do comparação incorreto, apenas um acorde dissonante era apresentado, sem acréscimo de pontos no contador. Após a apresentação das consequên- cias diferenciais para acertos e erros, um intervalo entre tentativas (IET) de $0,5 \mathrm{~s}$ era iniciado. Durante o IET, apenas o contador permanecia na tela. A Figura 1 ilustra as respostas de observação exigidas no presente experimento.

A tarefa de MTS com exigência de uma resposta para permitir visualizar os estímulos foi inicialmente proposta por Hamasaki (2009). A versão utilizada no presente experimento, denominada MTS com observação requerida (MTS-OR) foi a mesma utilizada no experimento de Perez (2012) e Perez, Tomanari e Vaidya (no prelo).

\section{Procedimento}

A descrição do procedimento foi realizada a partir de três momentos distintos ocorridos ao longo das sessões, a saber, (i) o estabelecimento do controle por rejeição; (ii) o ensino das relações condicionais de linha de base; e (iii) o teste das relações emergentes definidoras da formação de classes de equivalência. Vale ressaltar que essa divisão serve apenas à descrição do procedimento. Na prática, os participantes foram expostos a uma série continua de passos de ensino e teste. 


\section{Estabelecimento do controle por rejeição - Procedimento de enviesamento}

Os dois primeiros passos do procedimento tiveram por objetivo estabelecer um padrão de respostas que fosse prioritariamente baseado no controle por rejeição. Em ambos os passos eram utilizadas duas fotografias de animais (i.e., Z1 e Z2) como estímulos modelo e outras oito fotografias de animais como estímulos de comparação (i.e., Y1, Y2, $\mathrm{W}_{1}$, $\mathrm{W}_{2}, \mathrm{~W}_{3}, \mathrm{~W}_{4}, \mathrm{~W}_{5} \mathrm{e} \mathrm{W}_{6}$ ). De forma idêntica ao treino realizado por Johnson e Sidman (1993), o presente procedimento também utilizava quantidades diferentes de estímulos exercendo as funções de $\mathrm{S}+\mathrm{e}$ S-, ou seja, para cada modelo havia quatro estímulos de comparação exercendo a função de $S+$ e apenas um estímulo de comparação exercendo a função de S-. A Tabela 2 apresenta as configurações e quantidades de tentativas utilizadas em cada passo.

O Passo 1 contava com 16 tentativas divididas em dois blocos. Nas primeiras oito tentativas, apenas o estímulo modelo Z1 era apresentado. Nas oito tentativas finais, apenas o estímulo modelo Z2 era apresentado. O critério de aprendizagem consistia em 100\% de acertos em uma única sessão e índices menores eram seguidos pela repetição do passo. Caso o participante não atingisse o critério após cinco repetições, sua participação no experimento era interrompida.

O Passo 2, por sua vez, era composto por oito tentativas. Nesse caso, tentativas que apresentavam o estímulo Z1 como modelo eram alternadas de forma aleatória com tentativas que apresentavam o estímulo Z2 nessa mesma função. Novamente, o critério de aprendizagem consistia em $100 \%$ de acertos em uma sessão e índices menores ocasionavam a repetição do passo. Também de forma idêntica ao Passo 1, caso o participante não atingisse o critério após cinco repetições, sua participação no experimento era interrompida.

Tabela 2 - Estabelecimento do Controle por Rejeição. Configuração de Tentativas, Quantidade de Tentativas e Critério de Aprendizagem.

\begin{tabular}{|c|c|c|c|c|c|}
\hline \multirow[t]{2}{*}{ Passos } & \multicolumn{3}{|c|}{$\begin{array}{l}\text { Configuração de } \\
\text { Tentativas }\end{array}$} & \multirow[t]{2}{*}{$\begin{array}{l}\text { Quantidade de } \\
\text { Tentativas }\end{array}$} & \multirow[t]{2}{*}{ Critério } \\
\hline & $M$ & $\mathrm{~S}+$ & S- & & \\
\hline \multirow{8}{*}{$\begin{array}{l}\text { Passo } 1 \\
\text { Controle por Rejeição }\end{array}$} & $Z_{1}$ & $Y_{1}$ & $Y_{2}$ & 02 & \multirow{8}{*}{$\begin{array}{l}100 \% \text { de acertos em uma única } \\
\text { exposição }\end{array}$} \\
\hline & $Z_{1}$ & $\mathrm{~W}_{1}$ & $Y_{2}$ & 02 & \\
\hline & $Z_{1}$ & $\mathrm{~W}_{2}$ & $Y_{2}$ & 02 & \\
\hline & $z_{1}$ & $\mathrm{~W}_{3}$ & $Y_{2}$ & 02 & \\
\hline & $Z_{2}$ & $Y_{2}$ & $Y_{1}$ & 02 & \\
\hline & $\mathrm{Z}_{2}$ & $\mathrm{~W}_{4}$ & $Y_{1}$ & 02 & \\
\hline & $\mathrm{Z}_{2}$ & $\mathrm{~W}_{5}$ & $Y_{1}$ & 02 & \\
\hline & $z_{2}$ & $\mathrm{~W}_{6}$ & $Y_{1}$ & 02 & \\
\hline \multirow{10}{*}{$\begin{array}{l}\text { Passo } 2 \\
\text { Controle por Rejeição }\end{array}$} & \multicolumn{3}{|c|}{ Total de tentativas por passo } & 16 & \multirow{10}{*}{$\begin{array}{l}100 \% \text { de acertos em uma única } \\
\text { exposição }\end{array}$} \\
\hline & $Z_{1}$ & $Y_{1}$ & $Y_{2}$ & 01 & \\
\hline & $Z_{1}$ & $\mathrm{~W}_{1}$ & $Y_{2}$ & 01 & \\
\hline & $Z_{1}$ & $\mathrm{~W}_{2}$ & $Y_{2}$ & 01 & \\
\hline & $Z_{1}$ & $\mathrm{~W}_{3}$ & $Y_{2}$ & 01 & \\
\hline & $Z_{2}$ & $Y_{2}$ & $Y_{1}$ & 01 & \\
\hline & $\mathrm{Z}_{2}$ & $\mathrm{~W}_{4}$ & $Y_{1}$ & 01 & \\
\hline & $\mathrm{Z}_{2}$ & $\mathrm{~W}_{5}$ & $Y_{1}$ & 01 & \\
\hline & $\mathrm{Z}_{2}$ & $\mathrm{~W}_{6}$ & $Y_{1}$ & 01 & \\
\hline & \multicolumn{3}{|c|}{ Total de tentativas por passo } & 08 & \\
\hline
\end{tabular}




\section{Ensino das relações condicionais}

\section{de linha de base}

Os Passos 3, 4 e 5 tinham por objetivo ensinar as relações condicionais entre os estímulos visuais abstratos. Também com o objetivo de estabelecer relações controladas prioritariamente por rejeição, a exemplo do que ocorria nos Passos 1 e 2, cada modelo era relacionado com quatro diferentes estímulos de comparação que possuíam a função de $\mathrm{S}+$ e com apenas um estímulo de comparação que possuía a função de S-. Assim sendo, no Passo 3, por exemplo, havia tentativas em que, diante do modelo A1, B1 exercia a função de S+ e B2 exercia a função de S-; em outras tentativas, diante do mesmo Al, $\mathrm{X} 1$ exercia a função de $\mathrm{S}+\mathrm{e} \mathrm{B} 2$ exercia a função de S-; e assim sucessivamente. A Tabela 3 apresenta as configurações e quantidades de tentativas utilizadas nos Passos 3, 4 e 5.

Tabela 3 - Relações Condicionais Experimentais Ensinadas. Configuração de Tentativas, Quantidade de Tentativas e Critério de Aprendizagem.

\begin{tabular}{|c|c|c|c|c|c|}
\hline \multirow[t]{2}{*}{ Passos } & \multicolumn{3}{|c|}{$\begin{array}{l}\text { Configuração de } \\
\text { Tentativas }\end{array}$} & \multirow{2}{*}{$\begin{array}{l}\text { Quantidade de } \\
\text { Tentativas }\end{array}$} & \multirow[t]{2}{*}{ Critério } \\
\hline & $M$ & S+ & S- & & \\
\hline \multirow{9}{*}{$\begin{array}{l}\text { Passo } 3 \\
\text { Treino AB }\end{array}$} & $A_{1}$ & $\mathrm{~B}_{1}$ & $\mathrm{~B}_{2}$ & 01 & \multirow{8}{*}{$\begin{array}{l}100 \% \text { de acertos em uma } \\
\text { única exposição ou } 87,5 \% \text { de } \\
\text { acertos em duas exposições } \\
\text { consecutivas }\end{array}$} \\
\hline & $A_{1}$ & $X_{1}$ & $\mathrm{~B}_{2}$ & 01 & \\
\hline & $A_{1}$ & $X_{2}$ & $\mathrm{~B}_{2}$ & 01 & \\
\hline & $A_{1}$ & $x_{3}$ & $\mathrm{~B}_{2}$ & 01 & \\
\hline & $A_{2}$ & $\mathrm{~B}_{2}$ & $\mathrm{~B}_{1}$ & 01 & \\
\hline & $\mathrm{A}_{2}$ & $X_{4}$ & $\mathrm{~B}_{1}$ & 01 & \\
\hline & $A_{2}$ & $X_{5}$ & $\mathrm{~B}_{1}$ & 01 & \\
\hline & $\mathrm{A}_{2}$ & $X_{6}$ & $\mathrm{~B}_{1}$ & 01 & \\
\hline & \multicolumn{3}{|c|}{ Total de tentativas por passo } & 08 & \multirow{9}{*}{$\begin{array}{l}100 \% \text { de acertos em uma } \\
\text { única exposição ou } 87,5 \% \text { de } \\
\text { acertos em duas exposições } \\
\text { consecutivas }\end{array}$} \\
\hline \multirow{8}{*}{$\begin{array}{l}\text { Passo } 4 \\
\text { Treino BC }\end{array}$} & $\mathrm{B}_{1}$ & $\mathrm{C}_{1}$ & $\mathrm{C}_{2}$ & 01 & \\
\hline & $\mathrm{B}_{1}$ & $X_{7}$ & $\mathrm{C}_{2}$ & 01 & \\
\hline & $B_{1}$ & $x_{8}$ & $\mathrm{C}_{2}$ & 01 & \\
\hline & $\mathrm{B}_{1}$ & $X_{9}$ & $\mathrm{C}_{2}$ & 01 & \\
\hline & $\mathrm{B}_{2}$ & $\mathrm{C}_{2}$ & $\mathrm{C}_{1}$ & 01 & \\
\hline & $\mathrm{B}_{2}$ & $X_{10}$ & $\mathrm{C}_{1}$ & 01 & \\
\hline & $\mathrm{B}_{2}$ & $X_{11}$ & $\mathrm{C}_{1}$ & 01 & \\
\hline & $\mathrm{B}_{2}$ & $X_{12}$ & $\mathrm{C}_{1}$ & 01 & \\
\hline \multirow{10}{*}{$\begin{array}{l}\text { Passo } 5 \\
\text { Treino CD }\end{array}$} & \multicolumn{3}{|c|}{ Total de tentativas por passo } & 08 & \multirow{10}{*}{$\begin{array}{l}100 \% \text { de acertos em uma } \\
\text { única exposição ou } 87,5 \% \text { de } \\
\text { acertos em duas exposições } \\
\text { consecutivas }\end{array}$} \\
\hline & $\mathrm{C}_{1}$ & $\mathrm{D}_{1}$ & $\mathrm{D}_{2}$ & 01 & \\
\hline & $\mathrm{C}_{1}$ & $X_{13}$ & $\mathrm{D}_{2}$ & 01 & \\
\hline & $\mathrm{C}_{1}$ & $X_{14}$ & $\mathrm{D}_{2}$ & 01 & \\
\hline & $\mathrm{C}_{1}$ & $X_{15}$ & $\mathrm{D}_{2}$ & 01 & \\
\hline & $\mathrm{C}_{2}$ & $\mathrm{D}_{2}$ & $D_{1}$ & 01 & \\
\hline & $\mathrm{C}_{2}$ & $X_{16}$ & $\mathrm{D}_{1}$ & 01 & \\
\hline & $\mathrm{C}_{2}$ & $X_{17}$ & $D_{1}$ & 01 & \\
\hline & $\mathrm{C}_{2}$ & $X_{18}$ & $\mathrm{D}_{1}$ & 01 & \\
\hline & Tote & ativas & passo & 08 & \\
\hline
\end{tabular}


O ensino das relações condicionais ocorria de forma sequencial, isto é, o participante era exposto ao treino de uma nova relação condicional somente depois de obter o critério de aprendizagem para a relação condicional que estivesse sendo ensinada. O Passo 3 estabelecia as relações condicionais entre os estímulos dos conjuntos A e B (Treino AB). O Passo 4 estabelecia as relações condicionais entre os conjuntos B e C (Treino BC). O Passo 5, por sua vez, estabelecia as relações condicionais entre os conjuntos C e D (Treino CD). Cada um dos passos era composto por oito tentativas e o critério de aprendizagem adotado em cada passo consistia em $100 \%$ de acertos em uma única sessão ou $87,5 \%$ de acertos em duas sessões consecutivas. A não obtenção do critério era seguida pela repetição do passo em questão. De forma idêntica ao que ocorria nos passos anteriores, caso o participante não atingisse o critério após cinco repetições, sua participação no experimento era interrompida.

\section{Tabela 4 - Relações Condicionais Experimentais Testadas. Configuração de Tentativas, Quantidade de} Tentativas e Critério de Aprendizagem

\begin{tabular}{|c|c|c|c|c|c|}
\hline \multirow[t]{2}{*}{ Passos } & \multicolumn{3}{|c|}{$\begin{array}{l}\text { Configuração de } \\
\text { Tentativas }\end{array}$} & \multirow{2}{*}{$\begin{array}{l}\text { Quantidade de } \\
\text { Tentativas }\end{array}$} & \multirow{2}{*}{$\begin{array}{l}\text { Critérios definidores de for- } \\
\text { mação de classes de equiva- } \\
\text { lência }\end{array}$} \\
\hline & $M$ & $\mathrm{~S}+$ & S- & & \\
\hline \multirow[t]{2}{*}{$\begin{array}{l}\text { Passo } 6 \\
\text { Teste de Transitividade BD }\end{array}$} & $\begin{array}{l}\mathrm{B}_{1} \\
\mathrm{~B}_{2}\end{array}$ & $\begin{array}{l}D_{1} \\
D_{2}\end{array}$ & $\begin{array}{l}D_{2} \\
D_{1}\end{array}$ & $\begin{array}{l}08 \\
08\end{array}$ & \multirow[t]{2}{*}{$\begin{array}{l}80 \% \text { de respostas compatíveis } \\
\text { com o treino }\end{array}$} \\
\hline & Tota & ativas & passo & 16 & \\
\hline \multirow[t]{2}{*}{$\begin{array}{l}\text { Passo } 7 \\
\text { Teste de Transitividade AD }\end{array}$} & $\begin{array}{l}A_{1} \\
A_{2}\end{array}$ & $\begin{array}{l}D_{1} \\
D_{2}\end{array}$ & $\begin{array}{l}D_{2} \\
D_{1}\end{array}$ & $\begin{array}{l}08 \\
08\end{array}$ & \multirow[t]{2}{*}{$\begin{array}{l}80 \% \text { de respostas compatíveis } \\
\text { com o treino }\end{array}$} \\
\hline & \multicolumn{3}{|c|}{ Total de tentativas por passo } & 16 & \\
\hline $\begin{array}{l}\text { Passo } 8 \\
\text { Teste de Simetria } \\
\text { DC }\end{array}$ & $\begin{array}{l}D_{1} \\
D_{2}\end{array}$ & $\begin{array}{l}\mathrm{C}_{1} \\
\mathrm{C}_{2}\end{array}$ & $\begin{array}{l}\mathrm{C}_{2} \\
\mathrm{C}_{1}\end{array}$ & $\begin{array}{l}08 \\
08\end{array}$ & \multirow[t]{2}{*}{$\begin{array}{l}80 \% \text { de respostas compatíveis } \\
\text { com o treino }\end{array}$} \\
\hline \multirow{3}{*}{$\begin{array}{l}\text { Passo } 9 \\
\text { Teste de Simetria } \\
\text { CB }\end{array}$} & \multicolumn{3}{|c|}{ Total de tentativas por passo } & 16 & \\
\hline & $\begin{array}{l}\mathrm{C}_{1} \\
\mathrm{C}_{2}\end{array}$ & $\begin{array}{l}\mathrm{B}_{1} \\
\mathrm{~B}_{2}\end{array}$ & $\begin{array}{l}\mathrm{B}_{2} \\
\mathrm{~B}_{1}\end{array}$ & $\begin{array}{l}08 \\
08\end{array}$ & \multirow[t]{2}{*}{$\begin{array}{l}80 \% \text { de respostas compatíveis } \\
\text { com o treino }\end{array}$} \\
\hline & Tota & ativas & passo & 16 & \\
\hline \multirow[t]{2}{*}{$\begin{array}{l}\text { Passo } 10 \\
\text { Teste de Reflexividade } \\
\text { DD }\end{array}$} & $\begin{array}{l}D_{1} \\
D_{2}\end{array}$ & $\begin{array}{l}D_{1} \\
D_{2}\end{array}$ & $\begin{array}{l}\mathrm{D}_{2} \\
\mathrm{D}_{1}\end{array}$ & $\begin{array}{l}08 \\
08\end{array}$ & \multirow[t]{2}{*}{$\begin{array}{l}80 \% \text { de respostas compatíveis } \\
\text { com o treino }\end{array}$} \\
\hline & Tota & ativas & passo & 16 & \\
\hline \multirow[t]{2}{*}{$\begin{array}{l}\text { Passo } 11 \\
\text { Teste de Reflexividade } \\
\text { CC }\end{array}$} & $\begin{array}{l}\mathrm{C}_{1} \\
\mathrm{C}_{2}\end{array}$ & $\begin{array}{l}\mathrm{C}_{1} \\
\mathrm{C}_{2}\end{array}$ & $\begin{array}{l}\mathrm{C}_{2} \\
\mathrm{C}_{1}\end{array}$ & $\begin{array}{l}08 \\
08\end{array}$ & \multirow[t]{2}{*}{$\begin{array}{l}80 \% \text { de respostas compatíveis } \\
\text { com o treino }\end{array}$} \\
\hline & \multicolumn{3}{|c|}{ Total de tentativas por passo } & 16 & \\
\hline
\end{tabular}




\section{Teste de relações emergentes}

Os Passos 6, 7, 8, 9, 10, 11 tinham por objetivo avaliar as relações condicionais emergentes que são usualmente descritas quando ocorre a formação de classes de estímulos equivalentes (Sidman \& Tailby, 1982). Para essa finalidade, duas alterações principais eram realizadas a partir do Passo 6. A primeira alteração consistia em retirar as consequências diferenciais para acertos e erros liberadas pelo computador. Os participantes eram informados dessa alteração antes de serem expostos ao Passo 6. A segunda alteração consistia na igualação da quantidade de estímulos exercendo a função de S+e S- .
Durante todas as sessões de teste, para cada modelo havia apenas um estímulo com função de S+ e um estímulo com função de S-.

As relações emergentes transitivas $\mathrm{BD}$ e $\mathrm{AD}$ eram testadas nos Passos 6 e 7, respectivamente; as relações emergentes simétricas $\mathrm{DC}$ e $\mathrm{CB}$ eram testadas nos Passos 8 e 9; os Passos 10 e 11 eram destinados a testar as relações emergentes reflexivas CC e DD. Cada um desses passos era composto por 16 tentativas e não havia qualquer critério de aprendizagem. A Tabela 4 apresenta as configurações e quantidades de tentativas utilizadas em todos os passos de teste, do $6 .^{\circ}$ ao $11 .^{\circ}$.

Tabela 5 - Quantidade de Exposições Necessárias até Critério para Cada Participante nos Passos de Estabelecimento do Controle por Rejeição e no Ensino das Relações Condicionais.

\begin{tabular}{|c|c|c|c|c|c|c|}
\hline \multirow[t]{2}{*}{ Identificação } & \multicolumn{2}{|c|}{$\begin{array}{l}\text { Estabelecimento do controle } \\
\text { por rejeição }\end{array}$} & \multicolumn{3}{|c|}{$\begin{array}{l}\text { Ensino das } \\
\text { relações condicionais }\end{array}$} & \multirow{2}{*}{ Tota } \\
\hline & Passo 1 & Passo 2 & $\begin{array}{l}\text { Passo } 3 \\
\text { Tr. AB }\end{array}$ & $\begin{array}{l}\text { Passo } 4 \\
\text { Tr. BC }\end{array}$ & $\begin{array}{l}\text { Passo } 5 \\
\text { Tr. CD }\end{array}$ & \\
\hline Partic. 01 & 06 & 01 & 02 & 05 & 02 & 16 \\
\hline Partic. 02 & 04 & 02 & 02 & 02 & 02 & 12 \\
\hline Partic. 03 & 02 & 01 & 03 & 01 & 02 & 09 \\
\hline Partic. 04 & 04 & 01 & 02 & 02 & 02 & 11 \\
\hline Partic. 05 & 02 & 01 & 03 & 04 & 03 & 13 \\
\hline Partic. 06 & 02 & 01 & 03 & 04 & 05 & 15 \\
\hline Partic. 07 & 04 & 01 & 04 & 04 & 01 & 14 \\
\hline Partic. 08 & 02 & 01 & 02 & 02 & 01 & 08 \\
\hline Partic. 09 & 05 & 01 & 02 & 02 & 02 & 12 \\
\hline Partic. 10 & 03 & 02 & 03 & 04 & 04 & 16 \\
\hline Partic. 11 & 04 & 03 & 04 & 02 & 04 & 17 \\
\hline Partic. 12 & 03 & 01 & 02 & 03 & 02 & 11 \\
\hline Partic. 13 & 05 & 01 & 02 & 04 & 02 & 14 \\
\hline Partic. 14 & 03 & 01 & 01 & 04 & 02 & 11 \\
\hline Partic. 15 & 02 & 02 & 02 & 02 & 02 & 10 \\
\hline Partic. 16 & 02 & 05 & 02 & 02 & 03 & 14 \\
\hline Partic. 17 & 03 & 01 & 05 & 02 & 04 & 15 \\
\hline Partic. 18 & 05 & 03 & 04 & 02 & 02 & 16 \\
\hline Partic. 19 & 05 & 01 & 03 & 02 & 04 & 15 \\
\hline Partic. 20 & 02 & 01 & 02 & 02 & 02 & 09 \\
\hline Partic. 21 & 05 & 04 & 02 & 02 & 03 & 16 \\
\hline Partic. 22 & 01 & 01 & 03 & 05 & 02 & 12 \\
\hline Partic. 23 & 03 & 02 & 01 & 02 & 03 & 11 \\
\hline Média & 3,3 & 1,7 & 2,6 & 2,8 & 2,6 & 13,0 \\
\hline
\end{tabular}




\section{Resultados}

De forma geral, os participantes atingiram os critérios de aprendizagem exigidos ao longo de todo o procedimento. A Tabela 5 apresenta a quantidade de vezes que os participantes foram expostos a cada passo até atingir os critérios. A mesma Tabela 5 apresenta a quantidade média de exposições em cada passo.

No que concerne a análise da quantidade média de exposições por passo, é possível observar que a maior quantidade de repetições foi registrada para o Passo 1, com média de 3,3 exposições. Essa quantidade de repetições provavelmente está relacionada ao fato de ser a primeira oportunidade na qual os participantes eram expostos tanto às tarefas de MTS quanto a um procedimento que tinha por objetivo estabelecer o controle por rejeição. $\mathrm{O}$ Passo 2, por sua vez, registrou a menor quantidade média de repetições, 1,7 sessões. Essa diminuição na quantidade média de repetições era esperada, uma vez que este passo apresentava as mesmas configurações de tentativas do Passo 1, tendo como novidade apenas a alternância dos modelos. Assim sendo, observa-se que mais da metade dos participantes atingiu o critério de aprendizagem em uma única sessão. As quantidades médias de repetições registradas para os Passos 3, 4 e 5 foram bastante similares entre si, próximas ou iguais a 2,6. Pode-se observar ainda que a quantidade média de exposições necessárias para que um participante atingisse todos os critérios de aprendizados dos passos descritos na Tabela 5 foi 13,0. De 23 participantes, 20 deles necessitaram de 10 ou mais exposições para completar essas etapas do procedimento.

A Figura 2 apresenta as porcentagens de acertos nos testes de relações condicionais emergentes. Como descrito anteriormente, a ocorrência do controle por rejeição é avaliada a partir de padrões específicos de respostas que englobam altos índices de acertos nos testes de simetria e de transitividade com estímulos separados por um número par de conjuntos nodais; ao mesmo tempo, tais padrões deveriam originar baixos índices de acertos nos testes de reflexividade e transitividade entre estímulos separados por um número ímpar de conjuntos nodais. No caso do presente estudo, considerou-se que uma porcentagem de acertos igual ou superior a 87,5\% (i.e., mínimo de 14 acertos em 16 tentativas) seria considerado como alto índice de acertos.
Além disso, considerou-se que uma porcentagem de acertos igual ou inferior a 12,5\% (i.e., máximo de 2 acertos em 16 tentativas) seria considerado como baixo índice de acertos.

A primeira relação testada foi a Transitividade BD. Por se tratar de conjuntos de estímulos separados por um número ímpar de conjuntos nodais, o controle por rejeição seria demonstrado caso os percentuais de acertos fossem próximos ou iguais a $0 \%$. Assim sendo, observa-se que apenas os participantes $06,09,21$ e 23 apresentaram um padrão condizente com o previsto, com percentuais de acertos que variaram entre $0 \%$ e $12,5 \%$. Em contrapartida, somente os participantes 07,14 e 20 atingiram índices de acertos superiores a $80 \%$. Os demais 16 participantes apresentaram porcentagens de acertos entre $30 \%$ e $60 \%$.

A segunda relação emergente testada também envolvia transitividade, mas, dessa vez, entre os conjuntos de estímulos A e D. Nesse caso, os conjuntos de estímulos analisados eram separados por um número par de conjuntos nodais e o controle por rejeição seria demonstrado se os percentuais de acertos fossem próximos ou iguais a 100\%. Uma inspeção visual parece sugerir que as porcentagens de acertos nos testes para a relação transitiva $\mathrm{AD}$ são superiores quando comparadas as porcentagens de acertos para a relação BD. Ainda assim, apenas sete participantes $(29,1 \%)$ apresentaram índices de acertos superiores a $80 \%$, a saber, os participantes 01, 02, 03, 04, 07, 22 e 23.

Além das relações transitivas $\mathrm{BD}$ e $\mathrm{AD}$, as relações simétricas DC e CB também foram testadas. Em ambos os casos, o controle por rejeição seria demonstrado por percentuais de acertos próximos ou iguais a $100 \%$. Cinco participantes no teste DC e sete participantes no teste CB obtiveram percentuais de acertos acima de $80 \%$.

O controle por rejeição prevê ainda que os participantes apresentariam percentuais de acertos próximos ou iguais a $0 \%$ nos testes de reflexividade DD e CC. Com relação ao teste DD, cinco participantes apresentaram o resultado esperado, enquanto 13 participantes atingiram percentuais superiores a $80 \%$ de acertos. Nos testes CC, por sua vez, sete participantes atingiram percentuais de acertos próximos ou iguais a $0 \%$ e 14 participantes atingiram percentuais superiores a $80 \%$ de acertos. 


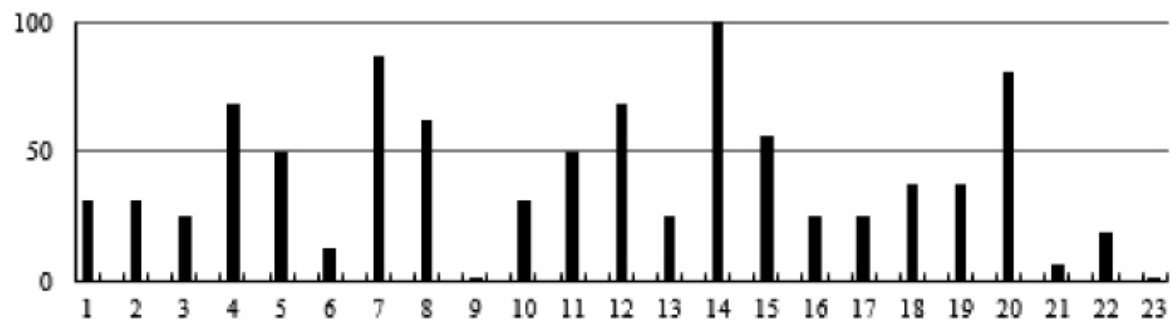

Transitividade BD

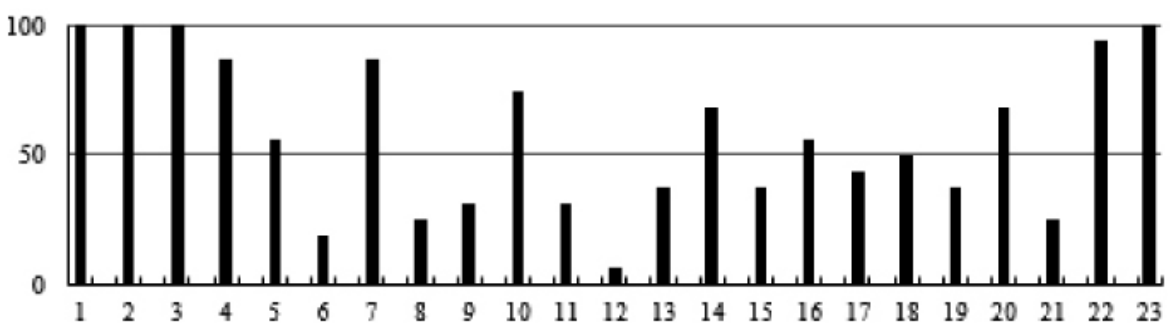

Transitividade AD

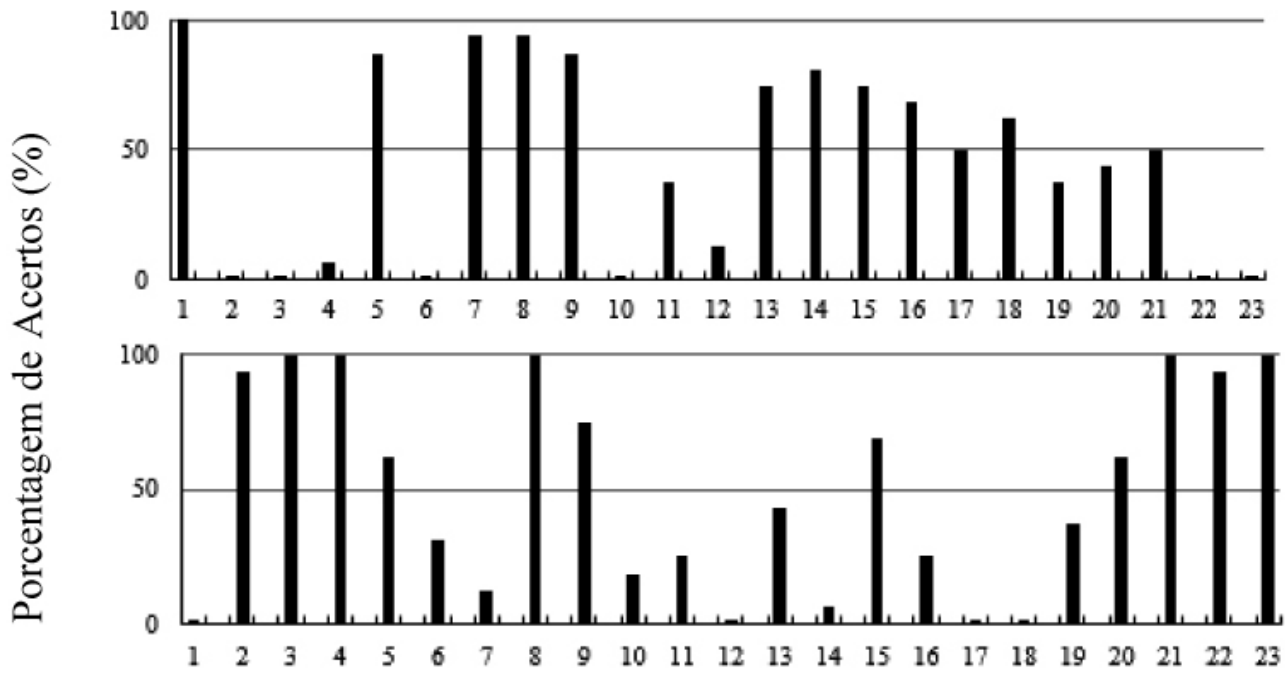

Simetria DC

Simetria $\mathrm{CB}$

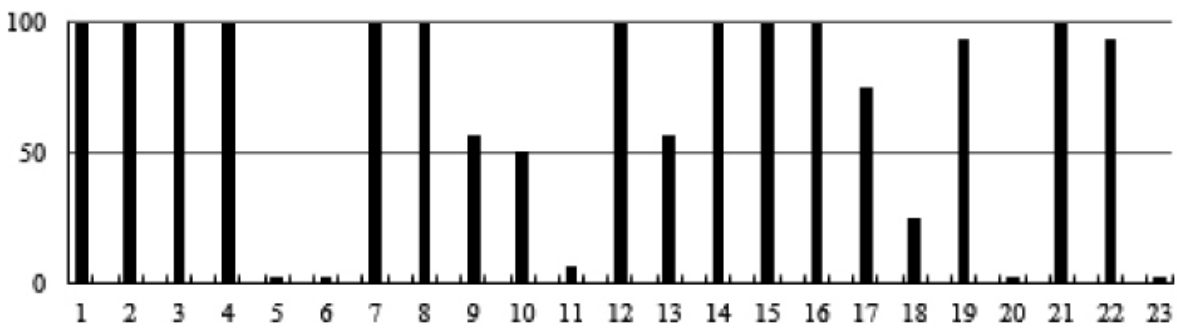

Reflexividade DD

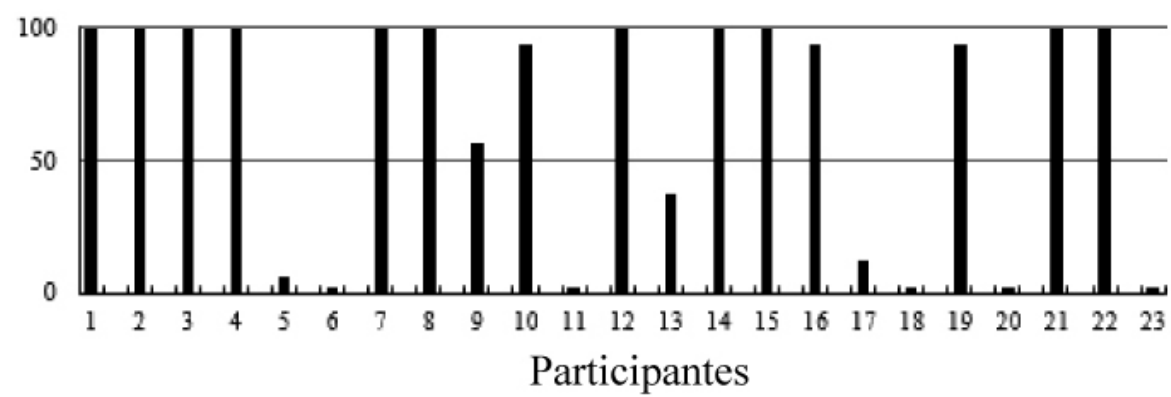

Reflexividade CC

Figura 2 - Porcentagem de acertos obtida por cada um dos participantes nos testes de relações emergentes definidoras da formação de classes de equivalência. 
A demonstração do controle por rejeição, no entanto, não ocorre a partir dos resultados obtidos de um único teste. Tal demonstração depende da análise conjunta dos resultados nos seis testes aplicados. Mais especificamente, apenas os índices de acertos próximos a $0 \%$ nos testes de reflexividade não podem ser considerados evidência de controle por rejeição. Seria necessário, para tanto, que esses resultados fossem acompanhados pelos resultados previstos tanto nos testes de simetria quanto nos testes de transitividade. A Tabela 6 apresenta um resumo do desempenho dos participantes no que se refere a ocorrência do controle por rejeição. Os quadrados pretos sinalizam as relações para as quais o critério para a ocorrência do controle por rejeição foi atendido. Vale ressaltar que índices iguais ou superiores a $87,5 \%$ nos casos em que o participante deveria apresentar $100 \%$ de acertos e escores iguais ou menores que $12,5 \%$ nos casos em que o participante deveria apresentar $0 \%$ de acertos foram considerados.

De maneira geral, é possível observar que apenas o participante 23 atingiu o critério para a ocorrência do controle por rejeição em cinco das seis relações testadas. Em contrapartida, os participantes 12 e 19 não atingiram o critério para nenhuma das relações testadas. Os participantes 03, 05, 06, 09 e 22, por sua vez, atingiram o critério para três relações. Os participantes 10, 14, 15 e 16 atingiram o critério para apenas uma relação. A maioria dos participantes, mais exatamente 12 deles, atingiu o critério para duas relações testadas.

A análise da Tabela 6 também parece indicar que não houve a predominância de uma ou outra relação testada. A quantidade de participantes que atingiu os critérios para a ocorrência do controle por rejeição foi muito similar entre todas as relações testadas. Os critérios para o teste de Transitividade $\mathrm{BD}$ foram alcançados em nove oportunidades; os critérios para o teste de Reflexividade DD em sete oportunidades; em todos os demais testes, os critérios foram alcançados em oito oportunidades.

\section{Discussão}

Participantes submetidos a procedimentos que favorecem a ocorrência do controle por rejeição em sua maioria não atingem as porcentagens de acertos que são usualmente esperados nos testes de formação de classes de equivalência (e.g., Arantes, 2012; Grisante, 2011; Hamasaki, 2009; Huziwara, de Souza et al., no prelo; Kato et al., 2008; Perez, 2012). No entanto, os padrões de respostas exibidos por esses mesmos participantes não são completamente opostos ao que seria esperado nos referidos testes, como descrito no experimento de Johnson e Sidman (1993 - ver também Perez et al., no prelo). Ao replicar sistematicamente o procedimento desenvolvido por Johnson e Sidman, o presente experimento procurou identificar padrões de respostas nos testes de formação de classes de equivalência que fossem comuns à maioria dos 23 participantes, mesmo que tais padrões fossem diferentes daqueles identificados no experimento original de 1993. Tais resultados poderiam auxiliar no entendimento dos processos comportamentais envolvidos na formação de classes e, talvez, definir com maior grau de precisão as situações nas quais o estabelecimento do controle por rejeição seja, de fato, a justificativa para o fracasso na formação de classes.

O estabelecimento do controle por rejeição era composto por dois passos (Passos 1 e 2) e o ensino das relações condicionais de linha de base era composto por três passos (Passos 3, 4 e 5). Caso não fossem cometidos erros, os participantes necessitariam de cinco exposições para atingir todos os critérios de aprendizagem estabelecidos. Como observado na Tabela 5, cada participante realizou, em média, 13 exposições, quantidade consideravelmente acima do mínimo necessário. Tais resultados são similares àqueles descritos em experimentos anteriores, nos quais houve a necessidade de um número elevado de sessões de treino para que os participantes atingissem os critérios de aprendizagem exigidos (Arantes, 2012; Grisante, 2011; Hamasaki, 2009; Huziwara, de Souza et al., no prelo; Magnunson, 2002; Perez, 2012).

Além das diferentes quantidades de estímulos com função de $\mathrm{S}+$ e $\mathrm{S}-$, o presente experimento optou por utilizar estímulos conhecidos durante o procedimento de enviesamento. Nos Passos 1 e 2, os estímulos utilizados foram fotografias de diferentes animais facilmente identificáveis. A hipótese seria que, ao utilizar estímulos conhecidos, o participante poderia identificar facilmente que o S- estava se repetindo ao longo das tentativas e isso iria facilitar o estabelecimento do controle por rejeição. Uma vez estabelecido esse controle, tal padrão 
comportamental seria aplicado quando estímulos abstratos fossem utilizados (i.e., Passos 3, 4 e 5). A análise dos resultados sugere que os participantes não tiveram dificuldades em atingir os critérios estabelecidos para os Passos 1 e 2, mas tal fato não garantiu necessariamente altas porcentagens de acertos nos demais passos.

De acordo com alguns autores, o padrão de rastreamento visual dos estímulos de comparação nas tarefas de MTS pode estar, em grande medida, relacionado à ocorrência do controle por rejeição (e.g., Huziwara, de Souza et al., no prelo; Huziwara, Silva, Perez, \& Tomanari, no prelo; Kato et al., 2008; Magnunson, 2002; Perez, 2008; Perez, Endemann, Pessôa, \& Tomanari, 2014; Pessôa, Huziwara, Perez,
Endemann, \& Tomanari, 2009). No experimento de Johnson e Sidman (1993), essa questão foi manipulada a partir da utilização de um procedimento de dica atrasada que consistia em retirar o $\mathrm{S}+$ da tela. Após a apresentação do estímulo modelo, dois estímulos de comparação eram apresentados simultaneamente (i.e., um S+ e um S-). Caso o participante não emitisse uma resposta de escolha dentro de um período pré-determinado, o S+ era retirado, restando apenas o S- visível na tela. A resposta correta, então, era escolher o quadrado vazio em que o $\mathrm{S}+$ fora anteriormente apresentado. Tal manipulação possivelmente produzia um aumento no tempo de observação dedicado ao S- e, consequentemente, um aumento na probabilidade de ocorrência do controle por rejeição.

Tabela 6 - Sumário do Desempenho Apresentado pelos Participantes nos Testes das Relações Emergentes. Quadrados Sinalizam as Relações para as Quais o Critério para a Ocorrência do Controle por Rejeição Foi Atendido.

\begin{tabular}{|c|c|c|c|c|c|c|c|}
\hline & Tran & dade & & & Refl & ade & \\
\hline & BD & $A D$ & DC & CB & DD & CC & Iotal \\
\hline Partic. 01 & & घ & घ & & & & 02 \\
\hline Partic. 02 & & घ & & п & & & 02 \\
\hline Partic. 03 & 匹 & घ & & घ & & & 03 \\
\hline Partic. 04 & & - & & ש & & & 02 \\
\hline Partic. 05 & & & घ & & ! & 口 & 03 \\
\hline Partic. 06 & घ & & & & ! & 口 & 03 \\
\hline Partic. 07 & & & घ & घ & & & 02 \\
\hline Partic. 08 & & & घ & घ & & & 02 \\
\hline Partic. 09 & घ & & घ & घ & & & 03 \\
\hline Partic. 10 & & घ & & & & & 01 \\
\hline Partic. 11 & & & & & п & 口 & 02 \\
\hline Partic. 12 & & & & & & & Zero \\
\hline Partic. 13 & घ & & घ & & & & 02 \\
\hline Partic. 14 & & & घ & & & & 01 \\
\hline Partic. 15 & & & घ & & & & 01 \\
\hline Partic. 16 & घ & & & & & & 01 \\
\hline Partic. 17 & घ & & & & & घ & 02 \\
\hline Partic. 18 & & & & & घ & घ & 02 \\
\hline Partic. 19 & & & & & & & Zero \\
\hline Partic. 20 & & & & & 口 & घ & 02 \\
\hline Partic. 21 & घ & & & घ & & & 02 \\
\hline Partic. 22 & घ & घ & & घ & & & 03 \\
\hline Partic. 23 & घ & घ & & घ & घ & घ & 05 \\
\hline Total & 09 & 07 & 08 & 09 & 06 & 07 & 46 \\
\hline
\end{tabular}


No presente experimento, o padrão de rastreamento dos estímulos foi controlado a partir da requisição de respostas de observação para visualizar os estímulos nas tarefas de MTS-OR (Perez \& Clavijo, 2010). O procedimento de MTS-OR e a necessidade da resposta de observação possibilitou que o tempo de visualização dos estímulos de comparação em cada tentativa fosse limitado a apenas 0,3 s. O curto período de visualização dos estímulos aliado a quantidade desigual de S+e S- deveria aumentar a probabilidade de estabelecimento do controle por rejeição no presente caso. O procedimento de MTS com exigência de resposta de observação foi originalmente utilizado por Perez (2012), também com o objetivo de estabelecer o controle por rejeição. Perez, no entanto, não apenas limitou o tempo de observação dos estímulos de comparação, mas também impediu que os estímulos com função de $\mathrm{S}+$ fossem visualizados em algumas tentativas. Quinze participantes divididos em três grupos foram submetidos ao procedimento. No primeiro grupo, os participantes eram impedidos de visualizar o $\mathrm{S}+$ em apenas $25 \%$ das tentativas de treino. Essa restrição era imposta em 50\% das tentativas para os participantes do segundo grupo. Finalmente, para o terceiro grupo, a restrição ocorria em 75\% das tentativas. Os resultados sugeriram que os padrões de respostas descritos nos experimentos de Johnson e Sidman (1993) para os testes de formação de classes ocorreram em maior quantidade no terceiro grupo, quando comparado ao primeiro e segundo grupos. Nossos achados parecem sugerir uma vez mais que o padrão de rastreamento dos estímulos de comparação pode explicar em grande medida a ocorrência do controle por rejeição. O presente experimento não utilizou tentativas com restrição de visualização do $S+e$, talvez por esse motivo, apenas um participante apresentou desempenho similar ao descrito por Johnson e Sidman. Em Perez et al. (no prelo), a combinação da restrição da observação aliado as diferentes quantidades de $\mathrm{S}+/ \mathrm{S}$ - produziu padrões de resposta muito similares aos descritos por Johnson e Sidman. Quando analisados em conjunto, os resultados sugerem muito fortemente que apenas a utilização de diferentes quantidades de S+/S- não parece suficiente para se produzir esse controle (Perez, 2008). Em estudos futuros, seria interessante repli- car o delineamento de grupos utilizado por Perez (2012). com as seguintes alterações: (i) introduzir um grupo controle no qual os participantes tivessem acesso a ambos os comparações em todas as tentativas (como realizado no presente experimento); e, também,(ii) aumentar a quantidade de participantes por grupo para avaliar se tanto os achados descritos por Perez (2012) quanto os descritos no presente experimento são confirmados quando submetidos a análises estatísticas pertinentes.

Com relação aos testes de formação de classes de equivalência, o participante 23 foi o único a apresentar os resultados consistentes com as predições de Carrigan e Sidman (1992) em cinco das seis relações emergentes testadas (a exceção ocorreu no teste de simetria DC). A maioria dos participantes apresentou os resultados consistentes com as predições em apenas duas ou três das seis relações emergentes testadas (ver Tabela 6 - coluna à direita). A análise dos resultados também indicou que, o fato de um participante ter apresentado os resultados previstos nos testes de transitividade, não garantiu que ele o fizesse nos testes de simetria ou reflexividade. Nos testes de transitividade e simetria, esse aspecto também pôde ser observado mesmo em uma análise intrarrelações. Ou seja, o fato de um participante ter apresentado os resultados previstos nos testes de simetria $\mathrm{DC}$, não garantiu que ele o fizesse no teste de simetria BC, por exemplo. Essa variação assistemática nos resultados, principalmente com relação à análise intrarrelações, parece sugerir que os resultados obtidos nos testes de transitividade e simetria não seriam indicadores confiáveis da ocorrência do controle por rejeição.

Os resultados obtidos nos testes de reflexividade, no entanto, apresentam um padrão diferente. Oito participantes apresentaram os resultados previstos nos testes de reflexividade CC. Destes, sete também apresentaram os resultados previstos nos testes de reflexividade DD. Assim sendo, diferentemente daquilo que foi descrito para os testes de transitividade e simetria, os nossos resultados parecem indicar que o controle por rejeição influencia os testes de reflexividade de forma mais regular do que o faz nos testes de transitividade e simetria.

De acordo com Sidman (1990), resultados positivos nos testes da relação emergente $\mathrm{BC}$, após treinos basais $\mathrm{AB}$ e $\mathrm{BC}$, implicaria a existência de 
reflexividade, afinal o participante deveria reconhecer o conjunto B que é apresentado como modelo (i.e., teste $\mathrm{BC}$ ) como sendo igual ao conjunto $B$ que é apresentado como comparação (i.e., treino AB). Tal suposição fez com que os testes diretos de reflexividade fossem suprimidos da grande maioria dos experimentos sobre a formação de classes. Perez (2012) afirma, no entanto, que resultados negativos nos testes de reflexividade podem ser considerados fortes indícios do estabelecimento do controle por rejeição, mesmo na ausência dos outros padrões de respostas previstos do Carrigan e Sidman (1992) e os resultados obtidos no presente experimento parecem confirmar tal argumento. Assim sendo, como salientado por Perez et al. (no prelo; ver também Perez, 2012), talvez fosse de grande utilidade reintroduzir testes diretos de reflexividade em experimentos sobre a formação de classes de equivalência com o objetivo de identificar de forma mais precisa os casos nos quais o controle por rejeição seria o responsável pela ocorrência de resultados negativos .

Mesmo diante das importantes contribuições oferecidas por experimentos sobre a ocorrência do controle por rejeição ao longo dos últimos 20 anos (Carrigan \& Sidman, 1992; Johnson \& Sidman, 1993; Kato et al., 2008; McIlvane et al., 1987; Sidman, 1987; Wilkinson \& McIlvane, 1997), ainda podem-se desenvolver novas estratégias relacionadas à maneira pela qual esse processo comportamental é avaliado. Nos testes tradicionalmente feitos, após o estabelecimento das relações condicionais $\mathrm{AB}$ e $\mathrm{BC}$, o teste de transitividade $\mathrm{AC}$ poderia apresentar A1 como modelo e $\mathrm{C} 1$ e C2 como comparações. Nesse caso, a escolha consistente do estímulo de comparação C2 diante do modelo A1 comprovaria a existência do controle por rejeição. Vale ressaltar que o controle por rejeição estabeleceu uma relação condicional entre os estímulos $\mathrm{A} 1$ e C1 (i.e., se A1, então não escolher C1), mas a existência de tal relação é comprovada ou inferida pela escolha do estímulo C2. Em suma, a ocorrência do controle por rejeição é comprovada a partir dos padrões de escolha exibidos pelos participantes (i.e., escolher C2), mas não avalia de forma direta a existência da relação condicional entre os estímulos A1 e C1. Uma alternativa proposta por Perez et al. (no prelo) consistiu em, após os testes de forma- ção classes, atribuir uma função específica para um dos estímulos da classe e avaliar como ocorria o procedimento de transferência de função. No caso de classes formadas por rejeição, a função atribuída ao estímulo A1 foi transferida para os estímulos B2, C1 e D2; de forma análoga, a função atribuída ao estímulo A2 foi transferida para os estímulos B1, C2 e D1, confirmando as previsões feitas por Carrigan e Sidman. Uma segunda alternativa também promissora para avaliar diretamente as relações condicionais existentes entre modelos e comparações incorretos se constituiria em registrar a ocorrência do componente de ativação cerebral denominado N400.

O N400 pode ser definido como um padrão de onda negativo cujo pico ocorre aproximadamente 400 milissegundos (ms) após a apresentação de um determinado estímulo e sua ocorrência têm sido frequentemente descrita em experimentos que utilizam o procedimento denominado priming semântico (Holcomb \& Anderson, 1993; Holcomb \& Neville, 1990). Em uma típica tentativa de priming semântico, pares de palavras são individual e sucessivamente apresentadas em uma tela de computador. A primeira palavra de cada par (priming) é apresentada por $400 \mathrm{~ms}$; após um intervalo de $750 \mathrm{~ms}$, a segunda palavra (target) é apresentada também por $400 \mathrm{~ms}$. Alguns pares são compostos por palavras que possuem um contexto semântico comum (e.g., masculino e feminino), enquanto outros pares são compostos por palavras que possuem contextos semânticos diferentes (e.g., masculino e celular). O padrão de ondas cerebrais é registrado durante e imediatamente após a apresentação da segunda palavra (target). Os resultados obtidos nesses experimentos demonstraram a ocorrência do N400 apenas nas tentativas em que os pares de palavras possuem contextos semânticos diferentes e, nesse sentido, esse padrão de onda cerebral é considerado uma medida do grau de incompatibilidade entre um determinado target e o contexto semântico previamente estabelecido por um determinado priming (Bortoloti, Pimentel, \& de Rose, 2014).

$\mathrm{O}$ registro do $\mathrm{N} 400$ em tarefas de priming semântico permite avaliar diretamente a existência de relações condicionais entre estímulos que supostamente pertenceriam a uma mesma classe de estímulos equivalentes (mesmo contexto semânti- 
co), sendo este o principal benefício ao estudo do controle por rejeição. O controle por rejeição daria origem a classes compostas por A1, B2, C1 e D2. Portanto, o N400 não deveria ser produzido quando o par de estímulos A1-C1 fosse apresentado, pois ambos os estímulos deveriam fazer parte da mesma classe, mesmo que o desempenho do participante em testes utilizando o MTS consista em escolher o comparação C2 diante do modelo A1. Segundo o mesmo raciocínio, o N400 deveria ser produzido quando o par de estímulos A1-D1 fosse apresentado, pois esses estímulos não deveriam fazer parte da mesma classe, mesmo que o participante apresente o padrão de escolher consistentemente o comparação D1 diante do modelo A1.

Assim sendo, o presente experimento procurou responder a questões ainda presentes na literatura e, adicionalmente, propor novas alternativas de experimentos para permitir um entendimento global do processo comportamental envolvido na formação de classes de estímulos equivalentes. Os dados encontrados somam-se aos demais apresentados pela literatura da área, indicando a necessidade de maiores refinamentos nos procedimentos para observação e demonstração do controle por rejeição.

\section{Referências}

Arantes, A. K. L. (2012). Topografias de controle de estímulos: Variações paramétricas do procedimento de máscaras (Tese de doutorado). Universidade Federal de São Carlos, São Carlos.

Bortoloti, R., Pimentel, N., \& de Rose, J. C. (2014). Electrophysiological investigation of the functional overlap between semantic and equivalence relations. Psychology \& Neuroscience, 7, 183-191. doi:10.3922/j.psns.2014.015

Carr, D., Wilkinson, K. M., Blackman, D., \& McIlvane, W. J. (2000).Equivalence classes in individuals with minimal verbal repertoires. Journal of the Experimental Analysis of Behavior, 74, 101-114.

Carrigan, P. F., \& Sidman, M. (1992). Conditional discrimination and equivalence relations: A theoretical analysis of control by negative stimuli. Journal of the Experimental Analysis of Behavior, 58, 499-504.

de Almeida, J. H. (2013). Estudos experimentais so- bre relações derivadas e transferência do significado (Tese de doutorado). Universidade Federal de São Carlos, São Carlos.

de Rose, J. C. (1993). Classes de estímulos: Implicações para uma análise comportamental da cognição. Psicologia: Teoria e Pesquisa, 9, 283-303.

Devany, J. M., Hayes, S. C., \& Nelson, R. O. (1986). Equivalence class formation in language-able and language-disable children. Journal of the Experimental Analysis of Behavior, 46, 243-257.

Dube, W. V., \& McIlvane, W. J. (1996). Some implications of a stimulus control topography analysis for emergent stimulus classes. In T. R. Zentall \& P. M. Smeets (Eds.), Stimulus class formation in humans and animals (pp. 197218). Amsterdam: Elsevier.

Fields, L., \& Verhave, T. (1987). The structure of equivalence classes. Journal of the Experimental Analysis of Behavior, 48, 317-332.

Goulart, P. R. K., Mendonça, M. B., Barros, R. S., Galvão, O. F., \& McIlvane, W. J. (2005). A note on select- and reject-controlling relations in the simple discrimination of capuchin monkeys (Cebus apella). Behavioural Processes, 69, 295-302.

Grisante, P. C. (2011). Controle de estímulos e formação de classes de estímulos equivalentes em crianças e em indivíduos com síndrome de down (Tese de doutorado). Universidade Federal de São Carlos, São Carlos.

Hamasaki, E. I. M. (2009). Respostas de observação na tarefa de pareamento ao modelo: Analisando topografias de controle de estímulos e seus efeitos sobre a formação de equivalência (Tese de doutorado). Universidade de São Paulo, São Paulo.

Holcomb, P. J., \& Anderson, J. E. (1993). Crossmodal semantic priming: A time- course analysis using event-related potentials. Language and Cognitive Processes, 8, 379-411.

Holcomb, P. J., \& Neville, H. J. (1990). Auditory and visual semantic priming in lexical decision: A comparison using event-related brain potentials. Language and Cognitive Processes, 5, 281-312.

Horne, P. J., \& Lowe, C. F. (1996).The origins of naming and other symbolic behavior. Journal of the Experimental Analysis of Behavior, 65, 185-241. 
Huziwara, E. M., de Souza, D. G., \& Tomanari, G. Y. (no prelo). Eye movements and the establishment of conditional relations controlled by selection and rejection. Psicologia: Reflexão e Crítica.

Huziwara, E. M., Silva, M. J., Perez, W. F., \& Tomanari, G. Y. (no prelo). Analyzing the stimulus control acquisition in simple discrimination tasks through eye movement. Psicologia: Reflexão e Crítica.

Johnson, C., \& Sidman, M. (1993). Conditional discrimination and equivalence relations: Control by negative stimuli. Journal of the Experimental Analysis of Behavior, 59, 333-347.

Kato, O. M., de Rose, J. C., \& Faleiros, P. B. (2008). Topography of responses in conditional discrimination influences formation of equivalence classes. The Psychological Record, 58, 245-267.

Magnusson, A. (2002). Topography of eye movements under select and reject control (Dissertação de mestrado). Northeastern University, Boston.

McIlvane, W. J., \& Dube, W. V. (1992). Stimulus control shaping and stimulus control topographies. The Behavior Analyst, 15, 89-94.

McIlvane, W. J., \& Dube, W. V. (2003). Stimulus control topography coherence theory: Foundations and extensions. The Behavior Analyst, 26, 195213.

McIlvane, W. J., Kledaras, J. B., Munson, L. C., King, K. A., de Rose, J. C., \& Stoddard, L. T. (1987). Controlling relations in conditional discrimination and matching by exclusion. Journal of the Experimental Analysis of Behavior, 48, 187- 208.

McIlvane, W. J., Serna, R., Dube, W. V., \& Stromer, R. (2000). Stimulus control topography coherence and stimulus equivalence: Reconciling test outcomes with theory. Em J. Leslie, \& D. E. Blackman (Eds.), Issues in experimental and applied analysis of human behavior. Reno: Context Press.

Perez, W. F. (2008). Movimentos dos olhos e topografias de controle de estímulos em treino de discriminação condicional e testes de equivalência (Dissertação de Mestrado). Universidade de São Paulo, São Paulo.

Perez, W. F. (2012). Equivalência de estímulos e transferência de função: Avaliando os efeitos dos controles por seleção e por rejeição (Tese de dou- torado). Universidade de São Paulo, São Paulo. Perez, W. F., \& Clavijo, A. (2010). Open the window. Laboratório de Análise do Comportamento. São Paulo: IPUSP. Programa de computador desenvolvido para a condução de pesquisas com humanos.

Perez, W. F., Endemann, P., Pessôa, C. V. B. B., \& Tomanari, G. Y.(2015). Assessing stimulus control in a discrimination task with compound stimuli: Evaluating testing procedures and tracking eye fixations. The Psychological Record, 65,83-88. DOI 10.1007/s40732-014-0092-1

Perez, W. F., \& Tomanari, G. Y. (2008). Controles por seleção e rejeição em treinos de discriminação condicional e testes de equivalência. Revista Brasileira de Análise do Comportamento, 4, 175190.

Perez, W. F., \& Tomanari, G. Y. (2013). Inferindo a ocorrência dos controles por seleção e rejeição em tarefas de emparelhamento com o modelo: Uma revisão metodológica. Acta Comportamentalia, 21, 211-225.

Perez, W. F., Tomanari, G. Y., \& Vaidya, M. (no prelo). Effects of select and reject control on equivalence class formation and transfer of function. Journal of the Experimental Analysis of Behavior.

Pessôa, C. V. B. B., Huziwara, E. M., Perez, W. F., Endemann, P., \& Tomanari, G. Y. (2009). Eye fixation to figures in a four-choice situation with luminance balanced areas: Evaluating practice effects. Journal of Eye Movement Research, 2, 1-6.

Sidman, M. (1971). Reading and auditory-visual equivalences. Journal of Speech and Hearing Research, 14, 5-13.

Sidman, M. (1978). Remarks. Behaviorism, 6, 265 268.

Sidman, M. (1987). Two choices are not enough. Behavior Analysis, 22, 11-18.

Sidman, M. (1990). Equivalence relations: Where do they come from? Em D. E. Blackman \& H. Lejeune (Eds.), Behaviour analysis in theory and practice: Contributions and controversies (pp. 93-114). Hove, U.K.: Erlbaum.

Sidman, M. (1994). Equivalence relations and behavior: A research story. Boston: Authors Cooperative. 
Sidman, M. (2000). Equivalence relations and the reinforcement contingency. Journal of the Experimental Analysis of Behavior, 74, 127-146.

Sidman, M. (2008). Symmetry and equivalence relations in behavior. Cognitive Studies, 15, 322332.

Sidman, M., \& Cresson, O. Jr. (1973). Reading and crossmodal transfer of stimulus equivalence in severe retardation. American Journal of Mental Deficiency, 77, 515-523.

Sidman, M., \& Tailby, W. (1982). Conditional discrimination vs. matching to sample: An expansion of the testing paradigm. Journal of the Experimental Analysis of Behavior, 37, 5-22.

Stromer, R., \& Osborne, J. G. (1982). Control of adolescents' arbitrary matching to sample by positive and negative stimulus relations. Journal of the Experimental Analysis of Behavior, 37, 329-348.

Wilkinson, K. M., \& McIlvane, J. W. (1997). Blank comparison analysis of emergent symbolic mapping by young children. Journal of Experimental Child Psychology, 67, 115-130.

Informações do Artigo

\section{Histórico do artigo:}

Submetido em: 28/04/2015

Primeira decisão editorial: 30/06/2015

Aceito em: 13/08/2015 